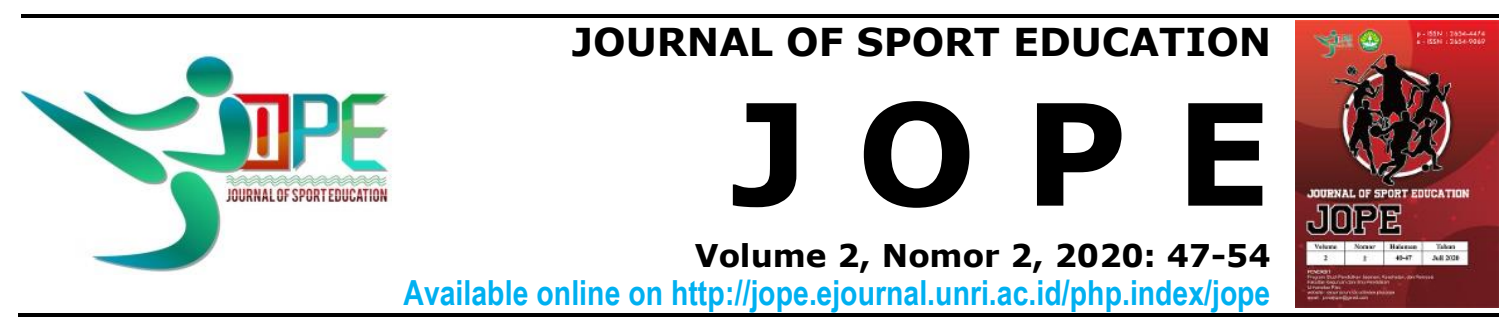

\title{
Identifikasi keberbakatan sepak bola pada siswa sekolah sepak bola hizbul wathan yogyakarta
}

\author{
Wahyu Wibowo Eko Yulianto \\ Fakultas Teknik Industri \\ Universitas Pembangunan Nasional Veteran Yogyakarta \\ wahyu.wibowo@upnyk.ac.id
}

Received: 13 Juni 2020; Revised: 19 Juni 2020; Accepted: 19 Juni 2020

doi http://dx.doi.org/10.31258/jope.2.2.47-54

\begin{abstract}
Abstrak
Penelitian ini bertujuan untuk mengidentifikasi bakat siswa Sekolah Sepak Bola Hizbul Wathan (SSB HW) Kota Yogyakarta secara ilmiah. Penelitian ini merupakan penelitian deskriptif dengan metode survei. Instrumen penelitian menggunakan tes Identifikasi Keberbakatan Sepak bola APORI. Subjek penelitian adalah Siswa SSB HW Kelompok Usia (KU) 11-13 tahun yang berjumlah 34 siswa. Teknik analisis data menggunakan sofftware keberbakatan sepak bola dan analisis deskriptif presentase. Hasil penelitian menunjukan bahwa keberbakatan siswa SSB HW Kota Yogyakarta KU 11-13 Tahun berada pada sebaran kategori kategori sangat kurang berbakat, kurang berbakat , cukup berbakat, Berbakat, dan sangat berbakat. Berdasarkan nilai rata-rata nilai yang didapat dapat disimpulkan bahwa tingkat keberbakatan siswa SSB HW Kota Yogyakarta masuk dalam kategori "Cukup Berbakat". Hasil ini dipengaruhi oleh beberapa faktor yaitu: Genetik (keturunan), Biologis (gizi dan neurologik), dan Lingkungan (orang tua, latihan dan pelatih)
\end{abstract}

Kata Kunci: keberbakatan, sepak bola, sekolah sepak bola

\section{Identify soccer talent in soccer school students hizbul wathan yogyakarta}

\begin{abstract}
This study aims to identify the talents of students of the Yogyakarta Hizbul Wathan Football School (SSB HW) scientifically. This research is a descriptive study with a survey method. The research instrument used the APORI Football Talent Identification test. The subjects of the study were the students of SSB HW Age Group (KU) 11-13 years, totaling 34 students. The data analysis technique was using football giftedness software and percentage descriptive analysis. The results showed that the giftedness of SSB HW students in Yogyakarta City KU 11-13 Years was in the category of very less talented, less talented, quite talented, Gifted, and very talented. Based on the average of value, it can be concluded that the level of giftedness of SSB HW students in Yogyakarta is included in the category of "Fairly Gifted". This result is influenced by several factors, namely: Genetic (hereditary), Biological (nutritional and neurological), and Environment (parents, training and trainers)
\end{abstract}

Keywords: giftedness, football, football school

How To Cite: Yulianto, Wahyu Wibowo Eko. (2020). Identifikasi keberbakatan sepak bola pada siswa sekolah sepak bola hizbul wathan yogyakarta. Journal of Sport Education (JOPE), 2 (2), 47-54. 
Journal of Sport Education (JOPE), 2 (2) 2020 - 48

\section{PENDAHULUAN}

Wahyu Wibowo Eko Yulianto

Olahraga merupak

keilmuan yang sangat potensial untuk

dikembangkan. Olahraga juga merupakan hal yang sangat penting untuk dikembangkan oleh suatu negara. Salah satu sisi pentingnya olahraga dikembangkan oleh suatu negara adalah sebagai alat untuk mengangkat harkat dan martabat, serta pemersatu suatu bangsa. Sebagai contoh negara dengan prestasi tinggi di ajang kejuaraan dunia akan dikenal sebagai negara yang maju dan dipandang lebih tinggi oleh negara-negara lain.

Namun tidak dapat dipungkiri, dari berbagai kejuaraan dunia, cabang sepak bola merupakan cabang olahraga yang paling populer dan paling dinanti. Hal tersebut didasarkan pada semua komponen atau tingkatan kelompok yang memainkan olahraga tersebut.

Berbicara tentang olahraga sepak bola kita akan langsung tertuju pada benua Eropa yang menjadi kiblat dunia sepak bola. Selain prestasi timnas dan liga negaranegara dikawasan Eropa yang sudah sangat maju, penggunaan teknologi, sistem pelatihan dan pembinaan pemain juga sudah terencana, terprogram dan berkelanjutan dengan sangat baik.

Hal serupa di Eropa tersebut saat ini juga sudah mulai berkembang di kawasan Asia termasuk Indonesia. Pengembangan dan penerapan teknologi, kurikulum dan sistem liga mulai diterapkan termasuk metode pemanduan bakat dengan secara ilmiah. Hal tersebut dilakukan dalam rangka sebagai usaha untuk memperbaiki sistem pembinaan guna mencapai prestasi maksimal. Sasaran pengembangannya tidak hanya di level klub tetapi juga hingga ditingkat nasional, demi meraih prestasi maksimal.

Akhir-akhir ini, angin segar di dunia sepak bola tanah air telah mulai ditunjukkan oleh prestasi Timnas U-16 dan U-19 serta adanya bebarapa pemain muda tanah air yang bahkan dikontrak oleh tim-tim Liga Asia dan Eropa. Sebut saja salah satunya Egy Maulana Fikri yang bermain untuk klub Lechia Gdansk dari negara Polandia. Dia merupakan hasil pembinaan Sekolah Khusus Olahraga Ragunan. Kita tahu bahwa untuk masuk ke Sekolah Khusus Olahraga tersebut harus melewati proses seleksi secara ilmiah yang cukup ketat.

Namun hal ini belum dijalankan di Sekolah-sekolah sepak bola yang ada di indonesia, banyak dari sekolah sepak bola hanya mensyaratkan siswa secara administratif bukan berdasarkan skill yang dimiliki atau jalur masuk tidak menggunakan sistem seleksi. Begitu juga dalam mengikuti program latihan, siswa tidak diukur terlebih dahulu kemampuan awalnya tetapi langsung masuk ke dalam latihan sesuai kelompok umurnya.

Padahal Peak performance dalam olahraga sepak bola tidak tercipta secara kebetulan, melainkan dari hasil persiapan atlet yang sangat cermat, berdasarkan program latihan terorganisir secara sangat rinci, direncanakan, bertahap, termonitor, objektif dan berkesinambungan (Harsuki, 2003) (Haugen \& Seiler, 2015). Untuk mencapai 


\section{Journal of Sport Education (JOPE), 2 (2) 2020 - 49}

\section{Wahyu Wibowo Eko Yulianto}

hal tersebut, tentunya dalam tahap awal diperlukan seleksi bakat para pemainnya.

Seleksi bakat merupakan tahap awal dalam mencari bibit-bibit pemain yang potensial. Pemanduan atau seleksi bakat merupakan metode sistematik guna memperkirakan atlet yang berbakat, mampu menjalani program latihan (Priya \& Santoso, 2012) (Kusnanik, 2014). Hal tersebut akan dijadikan dasar informasi kemampuan pemain terhadap pelatih sebagai dasar pelatihan mengelola atlet dan mengoptimalkan program latihan (Rohman, 2017), (Barreira, Garganta, Castellano, \& Anguera, 2013).

Sepak bola merupakan cabang yang kompleks, kombinasi dari beberapa aspek fisik, teknik, taktik, mental dan kekompakan terkandung didalamnya, serta merupakan cabang yang mempunyai karakteristik intensitas tinggi (Laitano, Runco, \& Baker, 2014). Untuk itu perlunya seleksi bakat dengan metode ilmiah perlu dilakukan tidak hanya pada Sekolah Khusus Olahraga tetapi juga di Sekolah-sekolah Sepak Bola yang ada diseluruh Indonesia, agar bibit-bibit berbakat yang dimiliki Indonesia dapat berkembang sesuai dengan jenjang dan dapat mencapai peak performance.

Sekolah Sepak Bola Hizbul Wathan Kota Yogyakarta merupakan salah satu SSB tertua di Kota Yogyakarta, SSB ini telah menelurkan pemain-pemain yang mampu berkiprah di liga indonesia. Sebut saja Nurohman Alwi, Sukamto pada masa Perserikatan memperkuat PSIM dan terbaru walaupun singkat Rangga Muslim pernah memperkuat tim PSIM Yogyakarta hingga ke PSS Sleman.

Beberapa nama di atas terbukti berbakat dan dapat mencapai prestasi tinggi. Hal ini menimbulkan pertanyaan, bagaimana dengan pemain yang lainnya. Mengapa hanya beberapa saja yang dapat muncul. Hal inilah yang kemudian menjadi fokus perhatian bahwa metode ilmiah untuk menyeleksi bibit pemain dalam sepak bola memang sangat perlu diterapkan. Kenyataannya, selama ini Sekolah Sepak Bola Hizbul Wathan Kota Yogyakarta belum menggunakan metode ilmiah dalam menyeleksi dan melakukan monitoring perkembangan pemain.

Hal ini mengakibatkan hasil program yang diterapkan oleh pelatih menjadi kurang maksimal. Perlunya penerapan metode seleksi awal bagi pemain baru, atau tes dan pengukuran bagi para pemain yang sudah ada di dalam Sekolah Sepak Bola Hizbul Wathan Kota Yogyakarta untuk melihat kemampuan dan perkembangannya sekaligus sebagai data bagi pelatih untuk memperbaiki dan mengembangkan program latihan yang akan disampaikan.

Untuk itu, maka diperlukan sebuah instrumen sebagai alat ukur yang dibutuhkan pelatih dalam proses mengukur kemampuan individu pemain. Saat ini, instrumen untuk mengukur kondisi fisik dan keterampilan atau kecakapan pemain sepak bola sudah banyak tersedia, mulai dari tes sirkuit yang berupa serangkaian tes untuk mengetahui proporsi tubuh, fisik dan kemampuan bermain, maupun tes untuk masing-masing item. Tes Identifikasi 
Journal of Sport Education (JOPE), 2 (2) 2020 - 50

Wahyu Wibowo Eko Yulianto

Keberbakatan Sepak Bola (APORI)

merupakan tes yang bertujuan untuk

mengetahui kemampuan fisik dan teknik dalam sepak bola (APORI, 2014)

Berdasarkan data tersebut penulis tertarik mengidentifikasi keberbakatan sepak bola pada siswa Sekolah Sepak Bola Hizbul Wathan Kota Yogyakarta KU 11-13 tahun. Sehingga nantinya dapat dijadikan dasar oleh para pelatih untuk menentukan program latihan dalam proses mengembangkan kemampuan pemain.

\section{METODE}

\section{Jenis Penelitian}

Penelitian deskriptif ini digunakan untuk mendeskripsikan atau menggambarkan data yang telah terkumpul sebagaimana adanya (Sugiyono, 2019). Penulis menggunakan pendekatan metode survei, sedangkan teknik pengumpulan data yang digunakan dalam penelitian ini menggunakan instrumen yang berupa tes keberbakatan sepak bola (APORI, 2014).

\section{Subjek Penelitian}

Sampel adalah bagian dari jumlah dan karakteristik yang dimiliki oleh populasi, maka sampel dapat diambil dari sebuah populasi (Sugiyono, 2019), Pengambilan sampel dalam penelitian ini dilakukan dengan total sampling. Sampel dalam penelitian ini adalah pemain Sekolah Sepak
Bola Hizbul Wathan Kota Yogyakarta KU 11-13 Tahun yang berjumlah 34 siswa.

\section{Instrumen Penelitian}

Instrumen pengumpulan data adalah alat bantu yang dipilih dan digunakan oleh peneliti dalam kegiatannya mengumpulkan data agar kegiatan tersebut menjadi sistematis dan dipermudah olehnya (Arikunto, 2006). Instrumen atau alat yang digunakan dalam penelitian ini berupa tes keberbakatan sepak bola (APORI, 2014). Item tes terdiri dari tes Antrophometri (TB dan BB), Tes Kemampuan Fisik (Speed Acceleration, Agility, Power, Speed Maximum, Beeptest), dan Keterampilan Teknik (David Lee Test dan Juggling)

\section{Teknik Analisis Data}

Teknik analisis data dalam penelitian ini menggunakan teknik analisis data deskriptif kuantitatif. Selanjutnya untuk menghitung persentase yang termasuk dalam kategori di setiap aspek digunakan rumus (Sudjono, 2009):

$$
\mathrm{P}=\frac{f}{N} \mathrm{x} 100 \%
$$

Keterangan:

$\mathrm{P}=$ angka persentase

$\mathrm{F}=$ frekuensi yang sedang dicari persentasinya

$\mathrm{N}=$ Number of Case (jumlah frekuensi)

Menentukan kriteria skor dengan menggunakan Norma Tes Keberbakatan dalam skala sebagai berikut:

Tabel 1. Norma Penilaian

\begin{tabular}{cc}
\hline Skor Keberbakatan & Kategori \\
\hline $\mathrm{X} \geq 1653,230$ & Sangat Berbakat \\
\hline $1519,330 \leq \mathrm{X}<1653,230$ & Berbakat \\
\hline $1385,429 \leq \mathrm{X}<1519,330$ & Cukup Berbakat \\
\hline $1251,529 \leq \mathrm{X}<1385,429$ & Kurang Berbakat \\
\hline $\mathrm{X}<1251,529$ & Sangat Kurang Berbakat \\
\hline
\end{tabular}


HASIL DAN PEMBAHASAN

Hasil

Dari analisis data keberbakatan sepak bola pada siswa SSB HW Kota Yogyakarta KU 11-13 tahun diperoleh skor terendah (minimum) 1222, skor tertinggi (maksimum)
1658, rerata (mean) 1474.86, nilai tengah (median) 1501.08, standar deviasi (SD) 104.876 .

Distribusi frekuensi ditampilkan dalam tabel 2 berikut ini:

Tabel 2. Distribusi frekuensi keberbakatan sepak bola pada siswa SSB HW Kota

Yogyakarta KU 11-13 tahun

\begin{tabular}{ccc}
\hline Interval & F & Kategori \\
\hline $\mathrm{X} \geq 1653,230$ & 1 & Sangat Berbakat \\
\hline $1519,330 \leq \mathrm{X}<1653,230$ & 11 & Berbakat \\
\hline $1385,429 \leq \mathrm{X}<1519,330$ & 16 & Cukup Berbakat \\
\hline $1251,529 \leq \mathrm{X}<1385,429$ & 4 & Kurang Berbakat \\
\hline $\mathrm{X}<1251,529$ & 2 & Sangat Kurang Berbakat \\
\hline Jumlah & 34 & \\
\hline
\end{tabular}

Apabila ditampilkan dalam bentuk grafik, siswa SSB HW Kota Yogyakarta KU 11-13 maka data keberbakatan sepak bola pada tahun tampak pada gambar berikut:

\section{Gambar 1. Diagram Batang keberbakatan sepak bola pada siswa SSB HW Kota Yogyakarta KU 11-13 tahun}

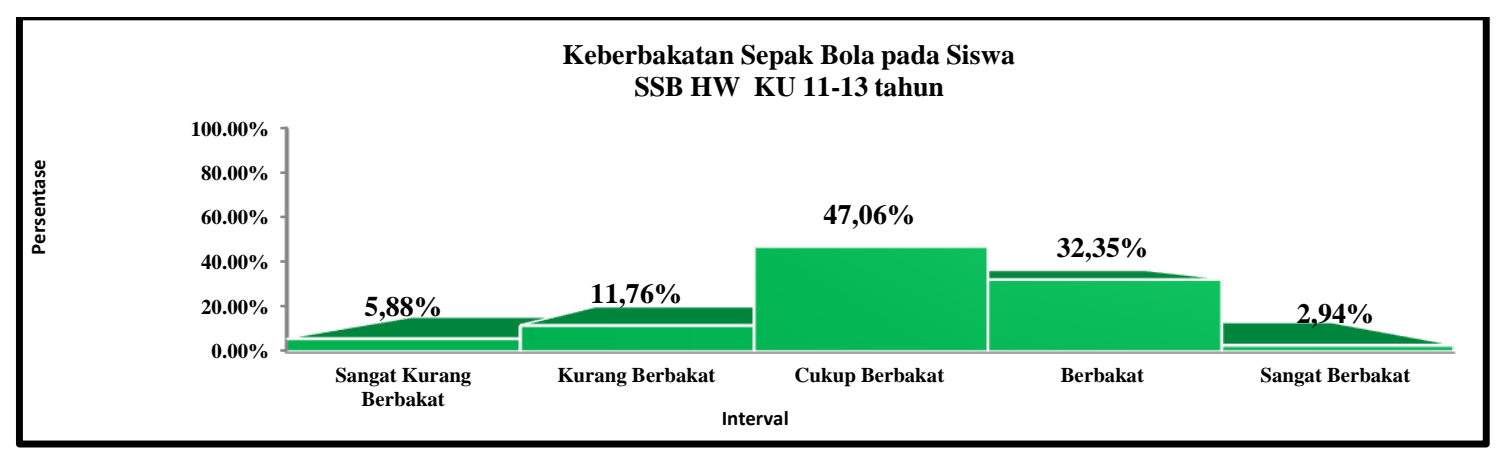

Berdasarkan tabel dan grafik di atas menunjukkan keberbakatan SSB HW Kota Yogyakarta KU 11-13 Tahun berada pada kategori "sangat kurang berbakat" sebesar $5,88 \%$ (2 pemain), kategori "kurang berbakat " sebesar $11,76 \%$ (4 pemain), kategori "cukup berbakat" sebesar 47,06\% (16 pemain), kategori "Berbakat" sebesar $32,35 \%$ (11 pemain), dan kategori "sangat berbakat" sebesar 2,94\% (1 pemain).
Sedangkan berdasarkan nilai rata-rata yaitu 1474.86, siswa SSB HW Kota yogyakarta masuk dalam kategori "Cukup Berbakat".

\section{Pembahasan}

Sebuah Peak performance dalam olahraga sepak bola tidak tercipta secara kebetulan, melainkan hasil dari persiapan atlet yang sangat cermat, berdasarkan program latihan terorganisir secara sangat rinci, direncanakan bertahap, termonitor, objektif 
Journal of Sport Education (JOPE), 2 (2) 2020 - 52

Wahyu Wibowo Eko Yulianto

dan berkesinambungan (Harsuki, 2003).

Untuk mencapai hal tersebut dalam tahap awal diperlukan seleksi bakat para pemain secara ilmiah.

Berdasarkan hasil penelitian diperoleh hasil kesimpulan bahwa tingkat keberbakatan sepak bola siswa SSB HW Kota Yogyakarta masuk dalam kategori "Cukup Berbakat". Hasil ini mengindikasikan bahwa siswa yang sudah diterima di SSB HW Kota Yogyakarta tidak hanya mempunyai motivasi untuk belajar sepak bola dan berprestasi tetapi juga mempunyai bakat dalam bidang sepak bola. Hasil ini juga menunjukan bahwa aspek Antrophometri, Fisik dan Skill sudah menunjukan cukup baik. Hal ini didasarkan dari instrumen tes yang mencakup ketiga hal tersebut.

Berdasarkan hasil tersebut terdapat 3 faktor yang penyebab keberbakatan yaitu Faktor Genetik (keturunan), Biologis (gizi dan neurologik), dan Lingkungan (orang tua, latihan dan pelatih) (Suntoro, 2012) (Idris, 2017) (Wangmuba, 2018).

Faktor Konsep diri pemain adalah gambaran yang dimiliki individu tentang dirinya; meliputi karateristik fisik, sosial, psikologis, emosional, aspirasi, dan prestasi. "Achievement motivation as a person's orien tations to strive for task success, persist in the face of failure, and experience pride in accomplishments" [19]. Motivasi berprestasi memberikan kesempatan kepada atlet untuk mencapai sesuatu dengan sempurna, meningkatkan kebugaran pada tingkatan tertinggi, dan berlatih secara maksimal.
Faktor pelatih mempunyai peranan penting dalam mengembangkan kecakapan pemain. Pelatih bak seorang arsitek bangunan, sehingga pelatih diharapkan mempunyai berbagai kompetensi yang memang dibutuhkan sebagai seorang pelatih. Kompetensi tersebut adalah lisensi kepelatihan, latar belakang melatih, kompetensi kepribadian. Lebih lanjut pelatih juga harus mempunyai syarat antara lain memiliki: (1) Kemampuan dan keterampilan cabang olahraga yang dibina, (2) Pengetahuan dan pengalaman di bidangnya, (3) Dedikasi dan komitmen melatih, (4) Memiliki moral dan sikap kepribadian yang baik (Sukadiyanto, 2002). Hasil kajian mendeskripsian bahwa lisensi dan latar belakang kepelatihan harus ditingkatkan oleh pelatih secara bertahap agar dapat meningkatkan kompetensinya dalam hal menyusun program latihan. Latar belakang atau pengalaman melatih juga sangat berpengaruh pada bagaimana pelatih dapat mengelola proses latihan. Kepribadian pelatih juga tidak kalah pentingnya. Seorang pelatih harus dapat mengajarkan dan mengembangkan karakter melalui suasana latihan (Doty, 2006) dan A person of charakter embodies both performance character and moral character (Davidson, 2004), kemampuan memotivasi, kemampuan teknik dan kemampuan penerapan strategi dalam pertandingan.

Telah terbukti bahwa beberapa negara yang menggunakan pemanduan bakat dapat mencapai prestasi tinggi, tercatat prosentase keberhasilan pencapaian prestasi atlet di 
Journal of Sport Education (JOPE), 2 (2) 2020 - 53

Wahyu Wibowo Eko Yulianto

negara-negara yang melakukan program https://doi.org/10.2174/1875399x0130

pemanduan bakat Rutten dan Ziemains 6010047

(2004) adalah sebagai berikut: China 50\%,

USA 72\%, Rusia 40\%, dan Australia 65,8\%

(Kusnanik, 2014).

\section{SIMPULAN}

Hasil penelitian menunjukan bahwa Keberbakatan Siswa SSB HW Kota Yogyakarta KU 11-13 Tahun berada pada kategori "sangat kurang berbakat" sebesar $5,88 \%$ (2 pemain), kategori "kurang berbakat" sebesar $11,76 \%$ (4 pemain), kategori "cukup berbakat" sebesar 47,06\% (16 pemain), kategori "Berbakat" sebesar 32,35\% (11 pemain), dan kategori "sangat berbakat" sebesar 2,94\% (1 pemain). Sedangkan berdasarkan nilai rata-rata yaitu 1474.86, siswa Sekolah Sepak Bola Hizbul Wathan Kota yogyakarta masuk dalam kategori "Cukup Berbakat". Hasil ini dipengaruhi oleh beberapa faktor yaitu: Genetik (keturunan), Biologis (gizi dan neurologik), dan Lingkungan (orang tua, latihan dan pelatih).

\section{DAFTAR PUSTAKA}

APORI. (2014). Panduan Identifikasi Bakat Istimewa Olahraga Sepakbola, Bolavoli, Bulutangkis, Pencak Silat. Yogyakarta: Direktorat Pembinaan PK-LK DIKDAS KEMENDIKBUD RI.

Arikunto, S. (2006). Prosedur Penelitian, Suatu Pendekatan Praktek. Yogyakarta: Andi offset.

Barreira, D., Garganta, J., Castellano, J., \& Anguera, M. T. (2013). SoccerEye: A Software Solution to Observe and Record Behaviours in Sport Settings. The Open Sports Sciences Journal.
Davidson, M. (2004). Developing performance character and moral character in youth. In The Fourth and Fifth Rs: Respect and Responsibility.

Doty, J. (2006). Sport building character. Journal of College and Character, 7(3).

Harsuki. (2003). Perkembangan olahraga terkini kajian para pakar. Jakarta: Rajagrafindo Persada.

Haugen, T., \& Seiler, S. (2015). Physical and Physiological Testing of Soccer Players: Why, What and How should we Measure? Sportscience Norway. Email. Reviewer: Martin Buchheit.

Idris, M. . (2017). Anak berbakat (Keberbakatan). Jurnal Pendidikan PAUD, 2(1).

Kusnanik, N. W. (2014). Model pengukuran antropometrik, fisiologis, dan biomotorik dalam mengidentifikasi bibit atlet berbakat cabang olahraga sepakbola. Pertemuan Ilmiah Ilmu Keolahragaan Nasional.

Laitano, O., Runco, J. L., \& Baker, L. (2014). Hydration science and strategies in football. Sports Science Exchange. https://doi.org/10.1111/j.17470080.2007.00199.x

Priya, N., \& Santoso, B. (2012). Pengembangan Instrumen Pemanduan Bakat Cabang Olahraga Anggar Menuju Atlet 2022 Instrument Development for Talent Scouting Fencing Athlete Achievement Towards 2022. Tahun.

Rohman, U. (2017). Evaluasi kompetensi pelatih sepakbola usia dini di sekolah sepakbola. Jurnal pendidikan jasmani dan olahraga. https://doi.org/10.17509/jpjo.v2i2.818 6

Sudjono, A. (2009). Pengantar Evaluasi 
Journal of Sport Education (JOPE), 2 (2) 2020 - 54

Wahyu Wibowo Eko Yulianto

Pendidikan. Jakarta: PT Raja Grafindo

Persada.

Suntoro, F. (2012). Survey pemanduan bakat atlet cabang olahraga sepak

Sugiyono. (2019). Metode Penelitian bola pada siswa sekolah dasar kelas $V$

Pendidikan (Kuantitatif, Kualitatif, di SD Negeri Karanganyar 01

Kombinasi, $R \& D$, dan Penelitian

Semarang. Universitas Negeri

Pendidikan). Bandung: ALFABETA.

Semarang.

Sukadiyanto. (2002). Teori dan metodologi melatih fisik petenis. Yogyakarta:

Wangmuba. (2018). Konsep diri.

UNY. 